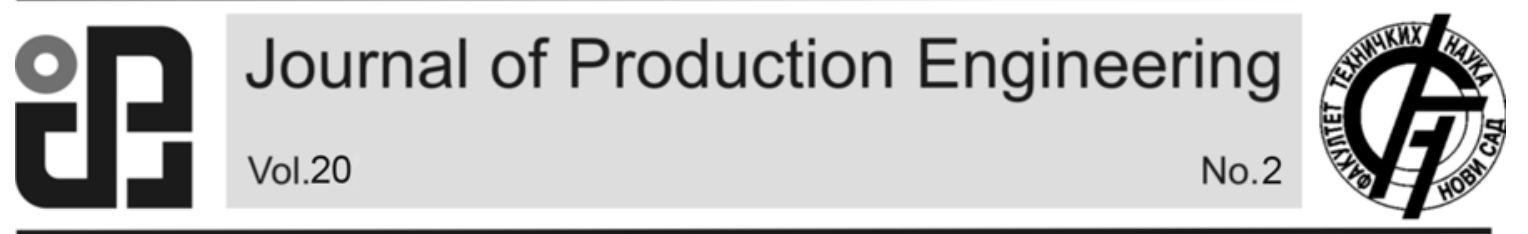

JPE (2017) Vol.20 (2)

Sekulić, S.

Original Scientific Paper

\title{
WEIBULL'S DISTRIBUTION FUNCTION - TERMS FOR MEAN TIME TO FAILURE: STRUCTURES, COMPARISON, DIFFERENCES AND APPLICABILITY
}

Received: 01 September 2017 / Accepted: 20 November 2017

Abstract: Two terms for determination mean time to failure, exist, first via gamma function, and second from distribution function for reliability or unreliability $R(t)=F(t)=0,5$, are analysed in this paper. Comparison both of terms pointed that the time to failure is direct proportional with position parameter $\eta$ and the gamma function $\Gamma$ corespond $K$ value, both in function of shape parameter $\beta$ also on differences between gamma $\Gamma$ and $K$ values and their application, to.

Key words: reliability, failure, mean time to failure, Weibull's distribution

Vejbulova funkcija raspodele - izrazi za srednje vreme bezotkaznog rada do otkaza: strukture, poređenje, razlike i primenljivost. U ovom radu su analizirana dva uslova za izračunavanje srednjeg vremena rada do otkaza, prvo preko gama funkcija, zatim preko funkcije pouzdanosti ili nepouzdanosti $R(t)=F(t)=0$,5. Poređenjem može se zaključiti da je vreme bezotkaznog rada direktno proporcionalno parametru razmere $\eta$ i gama funkciji $\Gamma$ odgovara vrednosti $K$, i u oba slučaja su u funkciji parametra oblika $\beta$, takođe $i$ razlika između $\Gamma i$ K vrednosti kao i njihove primene.

Ključne reči: pouzdanost, otkaz, srednje vreme rada do otkaza, Vejbulova raspodela

\section{INTRODUCTION}

Starting with probability positions mean time to failure can be determined on the basis of observed failures in time $[1,2,3,4]$.

Observed object in time can be described with simple state function

$$
x(t)=\left\{\begin{array}{l}
1 \text { object in available } \\
0 \text { object in failure }
\end{array}\right.
$$

The time in failure on observed object is not constant and present random value which we can prognose if it is known distribution function parameters and/or approximate - analytical or graphical $[3,5,6]$.

For discrete systems if we observe $N$ objects and if after time $t$ is $N(t)$ objects in available and $n(t)$ in failure, the reliability can be expressed as

$R(t)=N(t) / N=[N-n(t)] / N=n(t) / N$

and unreliability

$F(t)=1-R(t)=[1-N(t] / N[N-n(t)] / N=1-n(t) / N$

From previous equation follows

$R(t)+F(t)=1$

which indicates complementarities.

Frequency of failure is

$f(t)=\Delta n / N$

and intensity of failures

$\lambda=\Delta n / N(t)=f(t) / R(t)$ the mean time to failure is

$T_{m}=(1 / N) \Sigma \Delta n\left[\left(t_{i-1}+t_{i}\right)\right] / 2=\Sigma \Delta n t_{i m} / N$

where $\Delta n$ is the number of failures in interval $\Delta t$ and $t_{i-1}$ is the time on beginning and $t_{i}$ on the end of interval, and $t_{i m}$ the time in the middle of interval [7-9].

If the distribution function is known the reliability is

$R(t)=1-F(t)$

because it is

$R(t)+F(t)=1$

The frequency of failure as defined as

$f(t)=d R(t) / d t$

and failure intensity

$\lambda=f(t) / R(t)$

The mean time to failure by definition is

$T_{m}={ }_{0} \int^{\infty} R(t) d t$

and represent an area under a curve of reliability

$R(t)=f(t)$.

How is known Weibull's distribution function,

$F(t)=1-\exp (-t / \eta)^{\beta}$

which finds its application in analysis of reliability of technical systems.

The mean time to failure can be determined analytical via gamma functions

$T_{m}=\eta \Gamma(1+1 / \beta)$ 
As shown in $[9,10]$ mean time to failure correspond reliability i.e. unreliability $R(t)=F(t)=$ 0,5 and can be determined directly analytically [11].

$\mathrm{T}_{\mathrm{m}}=\eta[0,6931472]^{1 / \beta}$

\section{ANALYSYS OF TERMS FOR DETERMINATION OF MEAN TIME TO FAILURE}

On the above, mentioned mean time to failure can be determined analytically: [1,2] using Weibull's distribution function (12) for $\mathrm{R}(\mathrm{t})=\mathrm{F}(\mathrm{t})=0,5$.

Staring from Weibull's distribution function (12), mean time to failure $T_{m}$ can be determined directly from Weibull's distribution function for $R(t)=F(t)=$ 0,5 , from $[11,12]$ we have

$\mathrm{t}=\eta\left[-\ln (1-\mathrm{F}(\mathrm{t})]^{1 / \beta}\right.$

and for $\mathrm{F}(\mathrm{t})=\mathrm{R}(\mathrm{t})=0,5$

$\mathrm{t}=\mathrm{T}_{\mathrm{R}=0,5}=\mathrm{T}_{\mathrm{m}}$

$\mathrm{T}_{\mathrm{m}}=\eta[-\ln (1-0,5)]^{1 / \beta}=\eta C^{1 / \beta}$

where is $\mathrm{C}=0,6931472$

or

$T_{m}=\eta K$

where is

$\mathrm{K}=[-\ln (1-0,5)]^{1 / \beta}=C^{1 / \beta}$

\subsection{Applicability terms for determination mean time to failure}

How be fore is presented, mean time to failure, with two equation, in analytical form, can be determined

$$
\mathrm{T}_{\mathrm{m}}=\eta \Gamma(1+1 / \beta)
$$

$\mathrm{T}_{\mathrm{m}}=\eta(0,6931472)^{1 / \beta}=\eta \mathrm{K}$ where is $\mathrm{K}=\mathrm{f}(\beta)$

By comparing this terms we can conclude that the mean time to failure $\mathrm{T}_{\mathrm{m}}$ direct proportional with position parameter of Weibull's distribution function $\eta$. Values of gamma functions corresponds to values of $\mathrm{K}$.

Determination mean time to failure via gamma $\Gamma$ function

$$
T_{m}=\eta \Gamma(1+1 / \beta)
$$

demand use gamma function table $\Gamma$ or table $\mathrm{T} 1$

$$
\Gamma=f_{1}(\beta) \text {. }
$$

When in usage is equation

$$
\mathrm{T}_{\mathrm{m}}=\eta[0,6931472]^{1 / \beta}
$$

for calculation needs computer or calculator or slide rule or table $T 2, K=f_{2}(\beta)$, because shape parameter $\beta$ is in exponent.

But mean time to failure can be determined also, graphically from graphics $R(t)=f_{1}(t)$ and/or $R(t)=f_{2}(t)$ or via probalistic paper, for $R(t)=F(t)=0,5$ [12].

\begin{tabular}{|c|c|c|c|}
\hline $\boldsymbol{\beta}$ & $\boldsymbol{\Gamma}$ & $\boldsymbol{\beta}$ & $\boldsymbol{\Gamma}$ \\
\hline 0,2 & 120,00 & 2,5 & 0,887 \\
\hline 0,35 & 6,292 & 3,0 & 0,893 \\
\hline 0,5 & 2,000 & 4,0 & 0,906 \\
\hline 0,7 & 1,266 & 5,0 & 0,918 \\
\hline 1,0 & 1,000 & 6,0 & 0,928 \\
\hline 1,5 & 0,903 & 7,5 & 0,938 \\
\hline 2,0 & 0,886 & 10,0 & 0,965 \\
\hline
\end{tabular}

Table T1.

Table T.3, contain differences between gamma function $\Gamma$ and $\mathrm{K}$ values both in function of shape parameter $\beta$, are given.

Differences between gamma function and $\mathrm{K}$ values for $\beta \geq 2$ are smoler than $10 \%$.

\begin{tabular}{|c|c|c|c|}
\hline $\boldsymbol{\beta}$ & $\mathbf{K}$ & $\boldsymbol{\beta}$ & $\mathbf{K}$ \\
\hline 0,2 & 10,160 & 2,5 & 0,864 \\
\hline 0,35 & 0,349 & 3,0 & 0,885 \\
\hline 0,5 & 0,481 & 4,0 & 0,912 \\
\hline 0,7 & 0,592 & 5,0 & 0,929 \\
\hline 1,0 & 0,693 & 6,0 & 0,941 \\
\hline 1,5 & 0,803 & 7,5 & 0,952 \\
\hline 2,0 & 0,833 & 10,0 & 0,964 \\
\hline
\end{tabular}

Table T2.

\begin{tabular}{|c|c|c|c|c|}
\hline $\boldsymbol{\beta}$ & $\boldsymbol{\Gamma}$ & $\mathbf{K}$ & $\boldsymbol{\Gamma}-\mathbf{K}$ & $\mathbf{\%}$ \\
\hline 0,2 & 120,00 & 10,160 & $-40,000$ & 33,3 \\
\hline 0,35 & 6,292 & 0,349 & 5,943 & 94.5 \\
\hline 0,5 & 2,000 & 0,481 & 1,519 & 84,0 \\
\hline 0,7 & 1,266 & 0,592 & 0,674 & 53,2 \\
\hline 1,0 & 1,000 & 0,693 & 0,307 & 30,7 \\
\hline 1,5 & 0,903 & 0,803 & 0,100 & 11,1 \\
\hline 2,0 & 0,886 & 0,833 & 0,053 & 6,1 \\
\hline 2,5 & 0,887 & 0,864 & 0,023 & 2,6 \\
\hline 3,0 & 0,893 & 0,885 & 0,008 & 1,5 \\
\hline 4,0 & 0,906 & 0,912 & $-0,006$ & 0,7 \\
\hline 5,0 & 0,918 & 0,929 & $-0,011$ & 1,2 \\
\hline 6,0 & 0,928 & 0,941 & $-0,013$ & 1,2 \\
\hline 7,5 & 0,938 & 0,952 & $-0,014$ & 1,6 \\
\hline 10 & 0,965 & 0,964 & 0,001 & 3,4 \\
\hline
\end{tabular}

Table T3.

\section{CONCLUSION}

On the basis of before mentioned we can conclude:

- The mean time to failure can be determined:

- via gamma function $\Gamma$ and,

- from veiblle's distribution function, for $\mathrm{R}(\mathrm{t})$ $=F(t)=0,5$

in analytical form, 
- If comparing terms for mean time to failure in both cases first part is proportional with position parameter $\eta$, and second parts of terms are functions of shape parameter $\beta$,

- For calculation mean time to failure via gamma function $\Gamma$ the table of gamma function or table $\Gamma=\mathrm{fl}(\beta)$, needs use,

- How mean time to failure correspond to reliability and unreliability $\mathrm{R}(\mathrm{t})=\mathrm{F}(\mathrm{t})=0,5$, the mean time to failure can be determined from graphics $\mathrm{R}(\mathrm{t})=$ $\mathrm{f}_{1}(\mathrm{t})$ and/or $\mathrm{F}(\mathrm{t})=\mathrm{f}_{2}(\mathrm{t})$ or from probalistic paper,

- Differences between gamma function and $\mathrm{K}$ values (table T.3) are consequences of data processing by calculation values for gamma function table.

\section{REFERENCES}

[1] Todorovic, J., Zelenovic, D., Effectiveness of Systems in Mechanical Engineering, Naucna knjiga, Belgrade, 1981. (in Serbian).

[2] Kececioglu, D., Reliability Engineering Handbook, Vol. 1 \& Vol. 2, PTR Prentice Hall, Englewood Cliffs, New Jersey, 1991

[3] Ivanovic, G., Stanivukovic, D., Beker, I.: Reliability of technical systems, Edition: Faculty of Technical Sciences, Novi Sad, 2010 (in serbian: Pouzdanost tehničkih sistema);

[4] Sekulic, S., Statistical Formulation of a Cuttingtool Reliability in a Working Conditions, Reports of the 21th Conference of the European Organizations for Quality Control EOQC - Varna 77, Bulgaria, Varna, 1977.

[5] Sekulic, S., Methodologies for Determination of Cutting-tool Reliability, Drugie medzynarodove Symozium NARZEDZIA '84, Krakow - Janovice - Tarnow, Poland, 1984.

[6] Sekulic, S., Determination of Cutting-tool Reliability on Flexible Automatic Flow Lines,
Towardthe Factory of the Future, Proc. 8th ICPR, Aug., 1985, Springer-Verlag, Berlin- Heilderberg, New-York, okio, 1985.

[7] Sekulic, S., Graphical Procedure for Prognosis of the Cutting-tool Reliability on Flexible Automatics Lines Based on the Number of Work Pieces Machined with Particular Tools. Proc. INTRTRIBO '90, Sept. 1990, Budapest, 1990.

[8] Sekulic, S., Bogicevic, S., Dudic, S., Methodologies for Determination of Cutting-tool Reliability Supported by Computer, Proc. International Computer Science Conference Micro CAD '96, Febr. 1986, Miskolc, Hungary, pp 75-81.

[9] Sekulic, S., Reliability which Correspond Mean Time to Failure, CD-ROM Proc. XXX JUPITER Conference $17^{\text {th }}$ Symposium CAD/CAM, 2004, Belgrade, Serbia, 2004; (in Serbian)

[10] Sekulić, S., Tasić, N., Bogojević, B.: "Supporting Graphics for Determination of Mean Time to Failure of Technical Systems", 5. Life Cycle Engineering and Management, Beograd: Research Center DQM, 27-28 Jun, 2014, Belgrade, Serbia, pp. 46-51, ISBN 978-86-86355-17-1.

[11] Sekulic, S. About Mean Time to Failure Determination of Technical System, Proc. XVI International Scientific Conference on Industrial Systems (IS'14), Andrevlje, Novi Sad, Serbia, 1517 Oct. 2014,

[12] Sekulic, S. Reliability which correspond to mean time to failure, Journal of production Engineering, Vol. 18, No 1. Novi Sad 2015.

Autors: Prof . dr. Sava St. Sekulić

Department for Industrial Engineering and Management, Faculty of Technical Sciences, University of Novi Sad, 21000 Novi Sad, Dositej Obradović Square 7,

E-mail: nemanja.tasic@uns.ac.rs 


\section{APENDIX 1}

In goal to determine the mean time to failure of cutting tool $T_{m}$ and reliability $R(t)$, which corresponding the observation of cutting tool failure, by turning on the lathe, in real production conditions, by different cutting conditions, on operation turning, external, longitudinal, rough-finish, by machining cylinder head of engine "Perkins", type M3. The 25 different cutting conditions was varied (5 different cutting speeds $v$ and 5 different feeds $s$, in combination each with everyone. By grapho-analytical data processing, the distribution function parameters, for Weibull's distribution function $\beta$ and $\eta$, on the basis of that, the mean time to failure

$T_{m}=\eta \Gamma(1+1 / \beta)$ and reliability which corresponding $R\left(T_{m}\right)=\exp \left(-T_{m} / \eta\right)^{\beta}$ and $T_{R=0,5}$ which corresponding reliability or unreliability $R(t)=F(t)=0,5$. are determined. Quoted data are classified in Table T.4.

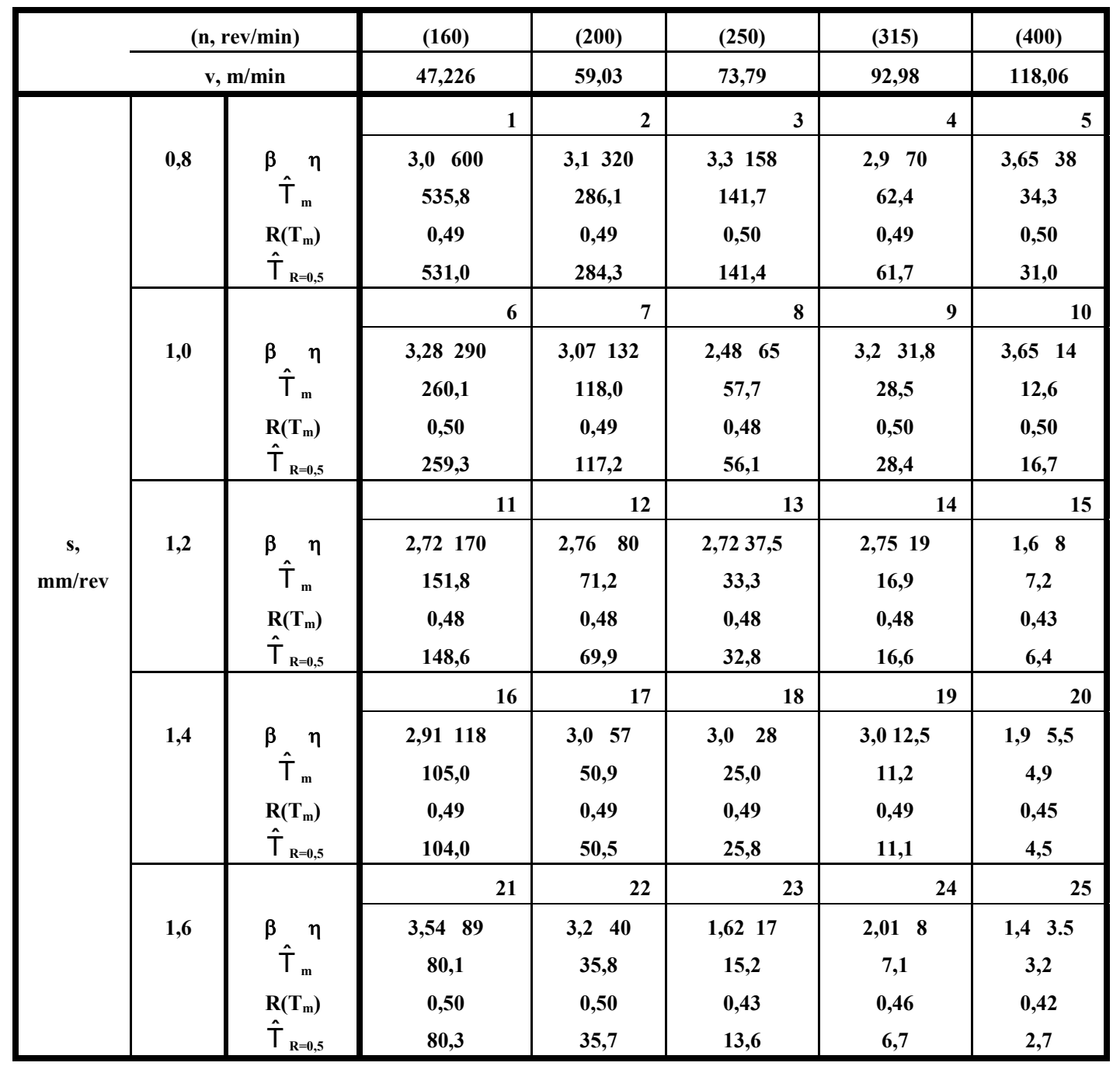

Table T.4. Estimated values of and correspond mean time to failure $\hat{T}_{m} i \hat{T}_{R=0,5}$

The table contains values of mean time to failure given from two equations

$T_{m}=\eta \Gamma(1+1 / \beta)$

and

$T_{m}=\eta\left[-\ln (1-0,5]^{1 / \beta}=\eta(0,6931472)^{1 / \beta}\right.$

which relates on same experimental data. 